\title{
Students Speak Out: The Impact of Participation in an Undergraduate Research Journal
}

Jordana Garbati

Wilfrid Laurier University

Esther Brockett

Wilfrid Laurier University

\section{Abstract}

Universities are places where writing plays a central role in knowledge creation and dissemination (Graves, 2011). Students engage with writing in their courses, at their institution's Writing Centre, and, perhaps more recently, in co-curricular projects such as an undergraduate research journal club. By participating in an undergraduate journal club, students develop critical thinking skills (Roberts, 2009), learn skills in research (Sandefur \& Gordy, 2016), and produce knowledge (Neville, Power, Barnes, \& Haynes, 2012). In this paper, we explore the impact of participation in a particular undergraduate research journal, the Undergraduate Journal of the Arts ${ }^{1}$ (UJA), on students' interactions with academic writing. To do so, we first surveyed the landscape of undergraduate research journals in Canada. We then conducted an online survey and interviewed the UJA's authors, editors, reviewers, and management board members. Our findings show that regardless of the roles they held at the UJA, participants benefitted from participation in terms of the development of their writing, interpersonal, and communication skills. We also discovered that participants faced time management constraints but were able to turn these obstacles into an opportunity to gain time management skills. Overall, our research has contributed to a sparse area of literature on undergraduate research journals. It also shows the value of an undergraduate research journal for student development.

Keywords: undergraduate student research, research journals, publication process 
Volume 28, 2018

http://journals.sfu.ca/cjsdw

\section{Introduction}

For several decades, opportunities have been created for undergraduate students to participate in collaborative research with faculty mentors (Caprio, 2014). Students develop inquiry skills, greater disciplinary knowledge, and enhance their communication skills through this collaborative research with faculty (Caprio, 2014). An increasing number of institutions now require oral or written communication to accompany undergraduate research experiences, and undergraduate publication is seen as a key activity to develop these skills (Caprio, 2014). However, the literature regarding undergraduate publications and students' experiences with these publications remains scarce. The limited and existing research reveals that the benefits of participation in undergraduate publishing include: awareness of peer-review, recognition on a resumé, and research literacy (Caprio, 2014, p. 148).

Considering the importance placed on undergraduate students' writing development, the increased opportunities for undergraduate research, and the limited body of literature in the area of undergraduate research publications, we set out to explore the impact of participation in an undergraduate research journal (URJ) on students' learning. Specifically, we focused our work on the Undergraduate Journal of the Arts (UJA), an interdisciplinary URJ housed at a mid-sized Ontario university, and its role in student engagement with academic writing. We also wanted to learn about the UJA's presence at the institution in general. Our research team consisted of a Writing Consultant at the institution's Writing Centre who was also the principal investigator of this project, and the seven students from the UJA's 2016-2017 management board.

This paper proceeds with the following sections: (a) a review of the literature in the area of undergraduate publishing, (b) a presentation of our methods of investigation, (c) a presentation of key findings, (d) a discussion of the findings, (e) a note about the limitations of our study, and (f) a commentary on the contributions of our work, not only for the research community, but for the participants of this study and for our research team.

\section{Literature Review}

This section reviews the literature on the engagement of students in academic writing and research, undergraduate journal clubs, the benefits of participation in URJs, and the management structure of URJs. 
Volume 28, 2018

http://journals.sfu.ca/cjsdw

\section{Engaging Undergraduate Students in Academic Writing and Research}

Universities are founded on a joint model of teaching and research with the expectation that students will learn as well as contribute new knowledge. To do so, students are expected to use and develop written communication skills during their time at university. Emig (1977) argues that as a mode of learning, writing is unique because it inherently creates opportunities for review of information; in addition, writing is both a process for learning and a product of learning. While teaching undergraduate students to write is given priority within many undergraduate institutions, Ozay (2012) advocates the necessity of incorporating research skills into the curriculum for undergraduate students. In this way, students can learn to be both consumers and producers of knowledge. Ozay points out that shifting forms of communication and information gathering in an internet-driven world create an even greater need for students to learn research and inquiry skills, which are now not only necessary for further academic pursuits but also for flourishing in other sectors and careers. Universities must provide multiple opportunities for students to gain writing and research skills while increasing their familiarity with research processes. In so doing, students will be better prepared for $21^{\text {st }}$ century challenges (Caprio, 2014).

\section{Undergraduate Journal Clubs}

Many universities are adopting undergraduate journal clubs as a way of engaging their students in the research process and the literature it produces (Clark, Rollins, \& Smith, 2014). These clubs are generally led by faculty, through whom students gain exposure to and experience with the research process and literature. These clubs take a variety of forms across institutions, but regardless of their structure, these clubs work toward similar goals. Sandefur and Gordy (2016) describe undergraduate journal clubs as a high-impact and low-cost opportunity for students to learn invaluable skills in applying the scientific and research process and also to engage, often for the first time, with primary research literature. Likewise, Roberts (2009) discusses how the undergraduate journal club works to expose students to peer-reviewed research and equips them with analytical and critical thinking skills as well as the confidence needed to approach research articles. Students who participate in these clubs are generally reading and analyzing journal articles as opposed to producing a journal. While undergraduate journal clubs offer one type of opportunity for undergraduate students to engage with research, other, perhaps more vibrant, opportunities can also be found through participation in undergraduate research journals. 
Volume 28, 2018

http://journals.sfu.ca/cjsdw

\section{Undergraduate Research Journals: Benefits of Participation}

Engagement in the publication of URJs creates opportunities for students to transition from being consumers to producers of knowledge (Neville, Power, Barnes, \& Haynes, 2012); this is a challenging experience but one which Ozay (2012) argues is necessary. One project, which reviewed 13 undergraduate political science journals and surveyed editors across the United States, found that URJs successfully promote undergraduate learning and development (Mariani, Buckley, Reidy, \& Witmer, 2013). Similarly, Marken (2015) looked at the ways in which Writing Centres can create and support undergraduate journals. As a case study, she described the undergraduate journal at her institution, which is co-run by the Writing Centre coordinator and several undergraduate students. Undergraduate student editors and authors involved in the institution's URJ valued exposure to the research process and considered themselves more prepared for future academic endeavours. In another study where students were surveyed about their experiences as editors and reviewers in the publication process of an URJ, findings showed that participants benefitted significantly from their experiences (Bauer, Ogas, Shakir, Oxley, \& Clawson, 2009). They gained interpersonal, academic, and intellectual skills through their participation. It is clear that URJs represent an interesting and valuable method of exposing students to research and is an opportunity for them to develop transferable skills.

\section{Undergraduate Research Journals: Management Structure}

Mariani et al. (2013) have noted that URJs exist at universities around the world but the organizational and management models and publishing processes of these journals vary greatly. They may be housed within a specific faculty, led by Writing Centre or Library staff, or governed by a student body. For instance, Stone, Jensen and Beech (2016) and Bauer et al. (2009) detail the different management models (e.g., led by faculty, involvement of graduate students) and publication processes (e.g., formation of selection panel and author feedback processes) of undergraduate journals at their respective institutions. Similarly, Cowell-Meyers, Mainwaring, Dugdale, Kinney, and Hanson (2015) describe the organizational model of their discipline-specific political science undergraduate research journal, Clocks and Clouds, and compare it with other journals mentioned in Mariani et al.'s research. In this example, a faculty member and an associate dean created the student journal, and faculty referrals are used to recruit a student reviewer team. Cowell-Meyers et al. discuss the common challenges and potential solutions faced by undergraduate journals at any institution, 
Volume 28, 2018

http://journals.sfu.ca/cjsdw

such as sustainability and motivating students to invest the necessary time and effort. Ho (2011) specifically looks at how a library can shape and support the organization and publication process of an undergraduate student-run journal. A library can provide a platform for journal hosting and acquaint students with scholarly publishing. In addition, Ho suggests that the library can connect students with other campus resources to ensure the journal's operation. In Marken's (2015) case, it is the Writing Centre that supports the institution's URJ. The spectrum of organizational structures used to run an URJ may impact the participants' particular experiences, but overall, URJs benefit the students who participate in their development. Because there are a limited number of URJs in Canada and abroad, we wanted to learn more about their structure. We used one URJ as a case study to delve into students' participation in the URJ and their perceptions of learning through the publication process.

To explore the management models of URJs, we searched for URJs online and gathered information from the websites of 11 URJs. Of the 11 URJs, eight were from Canada and are both multidisciplinary and interdisciplinary URJs with an online presence. The others were from England, Australia, and the Netherlands. As shown in Table 1, three URJs are from the sciences, and two from the arts. The two URJs from the arts, social sciences, or humanities publish journals on specific themes. Finally, the remaining four journals in our set are multidisciplinary.

Table 1. Scope of Publication of URJs

\begin{tabular}{ll}
\hline Scope & Number of URJs ${ }^{1}$ \\
\hline Arts & 2 \\
Arts, Social Sciences, Humanities & 2 \\
Sciences & 3 \\
Multidisciplinary & 4 \\
\hline
\end{tabular}

In terms of management structure, Table 2 shows that the majority of these URJs have a formal relationship with staff, faculty, or graduate students who offer support for the editorial and/or publication process. Only three URJs have no formal relationship with faculty, staff, or graduate students; one of these recently disbanded, one has recently published its second volume (at the University of British Columbia), and the third is one of two journals that are undergraduate studentled. 
Volume 28, 2018

http://journals.sfu.ca/cjsdw

Table 2. Management Model of Leadership of URJs

\begin{tabular}{ll}
\hline Management & Number of URJs $^{\mathbf{2}}$ \\
\hline Undergraduate students & 3 \\
Undergraduate and graduate students & 1 \\
Undergraduate and graduate students, faculty & 1 \\
Faculty & 1 \\
Undergraduate students and faculty & 2 \\
Graduate students & 1 \\
Undergraduate students and staff & 1 \\
\hline
\end{tabular}

Our institution's undergraduate student-led URJ serves as the focus of this study. ${ }^{3}$ This journal is unique in that it is the only one from the arts, social sciences, and humanities and does not publish its yearly publication on a specific theme. ${ }^{4}$ Given the UJA's unique position as a student-led interdisciplinary5 URJ, it provided an ideal site to learn more about the benefits of participation in an URJ.

\section{Overview of the UJA}

The UJA is an URJ that aims to engage its participants-authors, editors, reviewers, and management board members-in developing their understanding of research, academic writing, and the publication process. Beyond its local participants, the UJA hopes to engage its readers with highquality, peer-reviewed, academic research articles. The UJA is unique in that it is a student-driven endeavour.

The UJA was founded in 2011 by a pair of enthusiastic undergraduate students with the support of a few faculty members. After a couple of years of working through the challenges of running an URJ, Volume 1 of the UJA was published and released online and in print in the fall of 2014. The UJA has continued to publish an annual volume every fall since 2014, and UJA articles have been downloaded over 4300 times. $^{6}$

The UJA's management model consists of two boards: the management board and the editorial board. The management board consists of seven undergraduate student volunteers who hold positions (e.g., chair, secretary) throughout the year. These students are responsible for managing, publishing, and promoting the journal as well as continuously networking and expanding the reach and impact of the journal. The editorial board functions in the winter semester, and the group of approximately 20 undergraduate student volunteers are responsible for reviewing papers submitted for publication 7 and selecting the top seven or eight articles. These articles are then edited in 
Volume 28, 2018

http://journals.sfu.ca/cjsdw

preparation for publication. The UJA is generously funded by the institution's Arts Undergraduate Society (this organization is responsible for Faculty of Arts' student fees) and receives additional financial support from the Dean of Arts Office. While the UJA does not have a formal support relationship with any faculty, staff, or graduate students, the UJA benefits from a vibrant informal support network consisting of the Dean and Associate Deans of the Faculty of Arts, faculty, and writing consultants at the institution's Writing Centre. The members of the UJA boards connect with these people at various stages of the publication process to get advice and training.

\section{Research Objectives}

The overarching goal of this research was to learn more about the benefits of participation in an URJ. To do so, we were guided by the following research questions: (1) What are students' experiences of participation in the UJA? (2) What do UJA participants learn about academic writing and the publication process as a result of their involvement?

\section{Methodology}

Our research was led by a writing consultant at the institution's Writing Centre and a team of seven undergraduate students who also served as UJA management board members for the 2016-2017 academic year.

\section{Methods}

Our project employed a mixed methods approach (Creswell \& Plano Clark, 2007), consisting of surveys with qualitative and quantitative questions and semi-structured interviews. The mixed methods approach was best suited to answer our research questions as it allowed us to gain a detailed understanding of the impact of participation in the UJA on a large number of people while also helping us learn about participants' experiences in more detail. It also allowed us to focus on the academic writing aspect of our research, but, as we learned, it provided opportunities to learn about other experiences of UJA participants.

Before collecting data, our research team developed survey and interview questions, completed the Tri-Council Policy Statement training certificate, and submitted our research proposal to the institution's Research Ethics Board. We distributed surveys via email to potential participants. At the end of the survey, participants who had indicated an interest in participating in an interview were 
Volume 28, 2018

http://journals.sfu.ca/cjsdw

contacted and interviewed. Each interview was conducted by the principal investigator and one of the student researchers. Interview data was then transcribed by a third party.

To analyze the quantitative survey data (which included 4-point Likert scales), we used Excel to calculate descriptive statistics. To analyze the qualitative survey and interview data, we used QDA Miner software (Provalis Research, 2017). We conducted a content analysis through an open coding approach (Cohen, Manion, \& Morrison, 2017) to develop initial codes, to refine the codes, and to determine emerging themes. Pairs of research team members coded each interview (and qualitative data from the survey) to ensure accuracy in coding. Team members created summary reports to share data analyses with our full research team. In team meetings, we discussed results, confirmed themes, and addressed our research objectives.

To prepare for this research project, the research team completed four formal training sessions led by the principal investigator. These sessions focused on how to (a) develop survey and interview questions, (b) conduct semi-structured interviews, (c) analyze quantitative data, and (d) analyze qualitative data. Our team met informally on other occasions to provide project status updates, discuss findings, and draw conclusions. Three members of our team presented findings from this project at the Canadian Writing Centres Association Conference in Toronto in May 2017.

\section{Participants}

Any student who had been involved in the UJA in the position of editor, reviewer, author, or management board member between the UJA's establishment in 2011 and the winter of 2016 was invited to participate in our study. As no complete database of participant information existed, we developed a pool of potential participants through the acknowledgement sections in UJA publications, email records, Facebook, and LinkedIn contacts. Our initial survey invitation was sent via email to 39 people. Of these potential participants, 29 students participated in the survey. A total of 17 participants indicated an interest in an interview at the end of the survey and received a followup invitation. Of these, eight people participated in individual, semi-structured interviews.

The mixed methods approach and strong survey and interview response rates allowed our team to collect data from a range of participants in the UJA (i.e., authors, reviewers, editors, management board members). Table 3 shows the roles that survey participants held at the UJA; as noted, there was representation from all roles. Table 4 shows the gender distributions of survey participants; the majority of the participants were female. 
Volume 28, 2018

http://journals.sfu.ca/cjsdw

Table 3. Role of Survey Participants in the UJA

\begin{tabular}{ll}
\hline Role & Survey Participants (\%) \\
\hline Management Board Member & 33 \\
Reviewer & 29 \\
Editor & 26 \\
Author & 12 \\
\hline
\end{tabular}

Table 4. Gender of Survey Participants

\begin{tabular}{ll}
\hline Gender & Survey Participants (\%) \\
\hline Female & 59 \\
Male & 35 \\
Prefer Not To Say & 3 \\
Other & 3 \\
\hline
\end{tabular}

In the next section, we explore the findings from our data analysis.

\section{Findings}

In this section, we address four key themes that emerged from our data analysis: (a) writing development, (b) team work and interpersonal skills, (c) time management, and (d) other benefits.

\section{Writing Development}

The first major finding of our research was that participants, regardless of their position as author, editor, reviewer, or management board member, developed new writing skills through their participation with the UJA. Participants reported developing new writing abilities, including selfediting skills, critical reading skills, self-awareness through exposure to others' work, and a comprehensive understanding of the writing process. This writing development can be seen through survey data from authors (see Table 5) and editors/reviewers (see Table 6). As noted in Table 5, $100 \%$ of authors surveyed learned both how scholarly publication contributes to a research community and how to revise intensively following reader feedback. Additionally, 83\% of authors also learned how to improve the organization of a paper and how to manage the writing process in general. Likewise, 94\% of editors and reviewers surveyed learned how to evaluate the credibility of article authors, and 89\% learned about the process of publishing an article. Additionally, $67 \%$ found that they learned at least one new citation style through their experience with the UJA (see Table 6). The survey data indicates that writing development was a major benefit of participating in the UJA. 
Volume 28, 2018

http://journals.sfu.ca/cjsdw

Table 5. What Authors Learned While Participating in the UJA

\begin{tabular}{ll}
\hline Prompts & $\begin{array}{l}\text { Participants' } \\
\text { Responses } \\
\text { (\%) }^{\mathbf{8}}\end{array}$ \\
\hline $\begin{array}{l}\text { While participating in the UJA as an author, I learned... } \\
\text { How scholarly publication contributes to the research community }\end{array}$ & 100 \\
How to revise intensively following reader feedback & 100 \\
How to improve the organization of a paper & 83 \\
$\begin{array}{l}\text { How to manage the writing process in general (from research question } \\
\text { refinement to proofreading) }\end{array}$ & 80 \\
\hline
\end{tabular}

Table 6. What Editors/Reviewers Learned While Participating in the UJA

\begin{tabular}{lc} 
Prompts & $\begin{array}{l}\text { Pa } \\
\text { Re } \\
\text { While participating in the UJA as an editor/reviewer, I learned... }\end{array}$ \\
About the process for publishing an article & 83 \\
How scholarly publication contributes to the research community & 83 \\
How to evaluate the credibility of authors of articles & 94 \\
How to use at least one formatting style (e.g., MLA, APA) & 67 \\
\hline
\end{tabular}

Interview data confirmed that participants gained writing skills. For example, authors highlighted their new editing skills. One author said, "I used to be a one draft and done person...but...I actually review the things that I've written now, I try to look at them through different sorts of critical lenses, which I have not always been doing in the past" (Author M). Another author reflected on how the experience had made them more aware of the reach of their writing: "What else? Is kind of the question, regardless of if you're writing academic papers, if you're writing PR...anything that you're trying to achieve...both personally and professionally, it's just asking yourself, how can we take this further?" (Author J). Editors and reviewers highlighted the benefits of being exposed to the work of their peers. For instance, one reviewer spoke about how "You, for the first time, are exposed to a large cross section of the work of your peers...you get to see where your peers are" (Reviewer K). Another noted, "I think one of the things that you notice the most is that your writing is improved greatly by reading the writing of other people, and you're able to pick out what is good research, how to identify good sources, that sort of thing" (Reviewer S). They also mentioned that "oftentimes we make 
Volume 28, 2018

http://journals.sfu.ca/cjsdw

mistakes in our own work, that people pick out, and we never really understand why they're picking it out, but once you start to see it in other people's work, then you're like, oh I totally understand what that mistake is" (Reviewer S). Finally, management board members also discussed their writing development. For example, one Creative Director testified, "I realized that there's...planning that goes into writing each sentence in a paragraph, and...you have to kind of have the structure in your mind, rather than just...wading in and typing it all" (Creative Director F). Our data show that participants in all roles acquired new writing skills through their involvement with the UJA.

\section{Teamwork and Interpersonal Skills}

A second finding of our research showed that involvement in the UJA provided the opportunity for participants to gain teamwork and interpersonal skills. This was especially true for management board members, editors, and reviewers. In fact, survey data reveal that $91 \%$ of management board members claimed that the UJA taught them how to work collaboratively and that they gained valuable professional management experience. Interview data revealed this theme even more. For instance, we learned that editors and reviewers communicated with one another about the methods they used to review their papers. One participant said, "It's interesting talking to [other reviewers] about how they were getting through [the papers], and what methods they were doing to keep on top of them..." (Reviewer I). Likewise, management board members indicated that they gained interpersonal and teamwork skills; one member noted "As a member of the management board I learned how to work with a team, lead a group of people, shape an initiative and build a club's presence on campus." Others made similar comments: "there was a lot of team activity" (Secretary/Treasurer S), and "... the way we communicated with each other, I think that really helped in what I'm doing at work right now..." (Creative Director F). A founding Chairperson explained that the UJA was structured in a particular way for a reason, saying that, "I set it up so that each person had a defined role with defined tasks, but that allowed task sharing to occur between people" (Chairperson K).

\section{Time Management}

The third key finding of our research spoke to a challenging aspect of participating in the UJA for authors, editors, reviewers, and management board members. Specifically, participants found it challenging to manage their time commitments to the UJA along with their other priorities. In fact, time management was noted as the biggest challenge participants confronted while with the UJA. As 
Volume 28, 2018

http://journals.sfu.ca/cjsdw

one management board member noted, "[The journal] works under tight deadlines and relies on a tight team structure. That can be difficult at peak times because we are all students before we are on the board!" Authors also noted the challenge of time management in the survey. One participant said, "The largest challenge I experienced with [the journal] was the continuous editing of a paper that was not a part of my mandatory academic work load.... I was in my fourth year of university... and had many other assignments, projects and papers on my plate." Another author wrote, "There are a great many revisions and you must be able to complete them within the deadlines."

The theme of time management appeared in interviews as well. Management board members and reviewers, in particular, discussed the challenge of balancing the UJA with their academic and other commitments. One participant said, "[The journal is] like an extra course...depending on how involved you get" (Co-Editor in Chief W). Others noted similar issues: "You really need to manage your time effectively" (Chairperson K), and "[I] spent my weekends working on the journal...and then my evenings...It was a hectic task!" (Creative Director F). Reviewers also recognized the limited time for task completion: "There was a short period of time in which we had a lot of work to do... it's kind of constrained within a couple of weeks" (Reviewer I).

While participants clearly expressed the challenge of managing their UJA time with their academics and other commitments, they also considered that this challenge resulted in an opportunity to gain valuable skills in time management. Survey data revealed that $79 \%$ of editors and reviewers and 91\% of management board members indicated that they had faced a challenging learning experience. In interviews, participants discussed how the journal helped them manage their time: "[The journal is a] distraction that helps you focus more on your work" (Chairperson K), and "[It] really gave me a time management skill... and an understanding and appreciation of how much work goes into [this publication]" (Creative Director F).

\section{Other Benefits}

Our survey asked participants to note the benefits of participating in the processes of review and/or publication. As shown in Table 7, 75\% of participants indicated that participation in these processes helped them get into graduate school, $66 \%$ indicated that this experience helped them get into a professional college or competitive program, and 68\% indicated that the UJA helped their case for scholarship or award funding. Finally, $100 \%$ of survey participants indicated that participation in the review or publication process impressed their friends, family, colleagues, employers and professors. 
Volume 28, 2018

http://journals.sfu.ca/cjsdw

Table 7. Participants' Consideration of the Benefits of the Review and Publication Processes

\begin{tabular}{ll}
\hline Prompts & $\begin{array}{l}\text { Participants' } \\
\text { Responses (\%) }\end{array}$ \\
\hline Participating in the UJA ... & 75 \\
Helped me get into graduate school & 66 \\
Helped me get into a professional college or competitive program & 68 \\
Helped my case for scholarship or award funding & 100 \\
Impressed my friends, family, colleagues, fellow students, employers, and/or \\
professors
\end{tabular}

\section{Discussion}

Our data analysis revealed that UJA participants developed their writing, teamwork, interpersonal, and time management skills over the course of their involvement with the UJA. Our findings echo those of previous research regarding benefits from participation, including communication skill development (see Bauer et al., 2009; Caprio, 2014; Sandefaur \& Gordy, 2016). Beyond a club, the UJA provided a meaningful experience for participants whose roles and workload complimented their academic studies. Writing, teamwork, and time management skills are transferable to many contexts outside of university. Considering these benefits for students, URJs could be promoted as a cocurricular activity that provides opportunities for students to contribute to their academic communities and also gain valuable transferable skills.

Writing development was clearly the greatest benefit to participants in our study. Participants, regardless of their roles, found that their writing skills improved through participation in the various processes of publication (i.e., editorial, management, publishing). Further, authors benefitted from the work they did with the co-editors in chief as they prepared their papers for publication. The authors' own editing skills improved, and they also became more aware of the potential impact of their work. While participants may have previously considered research within the classroom framework, they could now see its position within the greater web of academia. Our findings align with Marken's (2015) work that revealed that students who had participated in an URJ felt better prepared for future projects. These findings have potential implications for how we teach students writing in the classroom and how institutions can promote engagement with writing in co-curricular experiences. Through participation in an URJ, students gain skills that can be applied to future studies or careers. Since participating in the editing and reviewing processes positively impacted participants' own writing development, we encourage faculty and student mentors to provide 
Volume 28, 2018

http://journals.sfu.ca/cjsdw

opportunities for peer review. Through the peer-review process, students can gain increased selfawareness of their own writing strengths, weaknesses, and habits. While we tend to see the value of peer review as an in-class activity, it can also serve students well in extracurricular activities such as an URJ. In our study, management board members, who were not directly involved with the peer review process, also gained knowledge of writing, which would likely contribute to their own writing development. With URJs requiring students to occupy various roles, they provide students with a multitude of opportunities to develop, learn, and contribute in ways that may help them with academic and non-academic work.

Participants also indicated that gaining experience in promotion and communication was valuable to them which may also have helped their development of writing skills. Participants who were not involved in the Arts (i.e., one participant had a computer science background) or familiar with academic writing also had an eye-opening experience that impacted their understanding of writing and how to write. An URJ such as the UJA allows students to write and to understand writing outside the traditional classroom context; in this way, the journal created a unique, valuable opportunity for writing development. As Ozay (2012) notes, post-secondary education curriculum should develop undergraduate students as producers of knowledge, develop their research skills, and allow them to flourish in projects beyond post-secondary education. Our research extends this notion into another context within the post-secondary institution. We call on students, instructors, and institutional leaders to consider supporting or beginning URJ work within their own contexts given the benefits noted in this and previous research.

In an URJ managed solely by undergraduate students, there were opportunities for teamwork and interpersonal skill development abound. One of the founding principles of the journal, we learned, was to generate opportunities for teamwork and shared learning. This vision has allowed its participants to engage in regular, close teamwork tasks. The UJA's team structure has allowed students to gain experience working with others to accomplish a variety of goals, including the overall goal of publishing an annual academic journal. While our research regarding teamwork revealed management board members' impressions, it is also noteworthy that editors and reviewers found opportunities to develop teamwork skills through the editorial process. By working with others to determine ways to manage the heavy workload of reviewing articles, they were able to share and complete their assigned UJA duties successfully. While URJ structures may vary, this research has shed light on the processes of an undergraduate-led journal. This approach may provide students with unique benefits that a faculty- or graduate student-led journal may not. 
Volume 28, 2018

http://journals.sfu.ca/cjsdw

As the area of research regarding URJs is sparse, our discussion adds to the literature by both confirming findings of previous research and suggesting new areas of inquiry. While our aim was to learn about UJA participants' experiences, in general and with academic writing, our data revealed other noteworthy findings.

One of our unexpected results relates to the challenge of time management. This finding has not been explored extensively in previous studies. Participants in our research noted that managing the workload for the UJA on top of their academic work, jobs, or other commitments could be quite challenging, particularly as their UJA work coincided with other stressful periods in the academic year. Participants indicated challenges regarding balancing the editing process while having to complete their own final papers and exams, reviewing papers within a limited time period, and managing the publication of an annual journal. In developing or leading an URJ, members should look carefully at the publication process and schedules in order to better balance their many demands. Although participants in our study were challenged to find time to commit to the journal, they noted the opportunity their busy schedules offered them for self-development in the area of time management. Balancing journal tasks, academic work, and additional activities taught them skills that they were then able to apply in other scenarios, such as the workplace. This situation created opportunities for students to grow and learn valuable skills for their futures. As the focus of our research was not to look in-depth at time management, it would be interesting to conduct further research in this area to learn about students' strategies and to engage other campus partners in URJ development. Since the UJA has a specific management structure, it would also be interesting to learn whether the challenge of time management that was present in our research exists in other URJs.

\section{Limitations}

While our research has shed light on the benefits and challenges of URJ participation for undergraduate students, our project is not without its limitations. While we had a relatively strong participation rate for both the survey and interview portions of our data collection, given our sample size, we know we were not able to reach all past participants. It was especially difficult to get in touch with former authors, and few of the authors agreed to participate in an interview. Ensuring that the URJ's management board maintains a current database of former participants would assist in conducting future research projects. It would have been interesting to learn more from authors about their experiences of the peer review process or their perceived value of writing a paper for an URJ publication. 
Volume 28, 2018

http://journals.sfu.ca/cjsdw

Another limitation to note was the development of our survey. We did not use an existing survey for this work, given the limited previous research available in the area. We also did not pilot the survey. Some questions may have been unclear to participants, which may have limited their interest in responding.

As we began to conduct interviews and analyze our data, we realized that it would have been beneficial to survey or interview other people who were involved with the UJA, but who did not play a central role. For example, the Writing Consultants at the Writing Centre and the Dean of Arts may have been able to provide input on their roles and experiences with the publication. These people were mentioned as supports in our data (e.g., in terms of writing training), but we did not have an opportunity to investigate these peoples' perspectives. By learning from others who are involved in the preparation of an URJ, best practices may be highlighted and challenges could be identified.

\section{Conclusion}

Our research has provided the writing community, the undergraduate publishing community, and others with insights into students' experiences participating in an URJ. In particular, our study revealed the benefits and challenges students have experienced through participation as authors, editors, reviewers, or management board members. Considering the sparse literature in the area of URJs, our work contributes to the field, has made explicit findings in the areas of peer review and time management challenges, and has given us a stronger understanding of management structures and peer-to-peer interactions in URJ participation. We call for additional research in the area of URJ structure: it would be valuable to complete a survey of URJs' management models and the experiences of those who manage URJs.

This research project and findings have created unexpected opportunities for reflection on the UJA's past and insight into the future of this URJ. Additionally, our project created an opportunityperhaps the first formal opportunity - for past participants to offer feedback on how to improve the UJA (e.g., its editorial processes). This research has led to multiple conversations about the management structure and the future plans of the journal; the research team (who were management board members at the time of the research) have been able to implement changes as a result of the research we conducted (e.g., post-publication meet-up, increased interaction between authors and editors). The insight we gained from this work has been invaluable for the UJA's future. It will continue to guide the UJA's board and inform future decisions around the UJA's publication process, editorial process, and organizational structure. 
Volume 28, 2018

http://journals.sfu.ca/cjsdw

For our research team, specifically, this research has given us the chance to connect and meet with other students and staff involved in managing URJs across Canada. These connections have enriched our own understandings of the UJA.

Finally, this project has validated the UJA's role at its institution and the efforts of many people involved in the journal over the past six years. Although the UJA's management board has been able to gauge interest in its publication through submissions and support from various university departments, the research project has highlighted the successes that undergraduate students have gained through participation in the journal.

\section{Notes}

1. The names of the journal and institution have been removed.

2. A Dutch journal was omitted as its management structure was unclear.

3. The other journal is at the University of British Columbia (Canadian Journal of Undergraduate Research/CJUR).

4. The other journal from the arts, social science, and humanities publishes its journal on a specific theme.

5. Interdisciplinary is used to refer to journals that encompass multiple disciplines within the arts/social sciences domain. Multidisciplinary is used to refer to journals that encompass both arts and sciences.

6. The number of downloads noted at the time of writing this paper. Articles are downloadable via Scholars Commons, the international repository for academic journals.

7. The journal receives approximately 200 submissions each year.

8. Responses from the "sufficient" and "considerable" amount categories on the 4-point Likert scale.

9. Responses from the "sufficient" and "considerable" amount categories on the 4-point Likert scale.

\section{Acknowledgements}

This project would not have been possible without the contributions of our team. Jordana Garbati was the principal investigator and oversaw the project. Esther Brockett was the lead undergraduate research student and actively participated in every step of the research process. She prepared the literature review and contributed extensively to the preparation of this article. Carina Rampelt led the development of the interview questions and made extensive contributions to the data analysis. 
Volume 28, 2018

http://journals.sfu.ca/cjsdw

Brittney Tessier provided valuable input on the coding and analysis of the quantitative data. Mitchell Kooh assisted in developing interview questions, conducted interviews, and did initial coding of the qualitative data. Vidish Parikh assisted in the development of interview and survey questions and conducted interviews. Madeline McInnis and Mynt Marsellus offered feedback at the initial and final stages of the research process. The entire team worked together on the Ethics Review Board application and conference proposal submission.

We would like extend our thanks to Dr. Edmund Pries who provided valuable feedback on an early draft of this paper.

\section{References}

Bauer, B. J., Ogas, W. C., Shakir, O. R., Oxley, Z. M., \& Clawson, R.A. (2009). Learning through publishing "The Pi Sigma Alpha Undergraduate Journal of Politics". The Teacher, 565-569.

Caprio, (2014). Student publishing: Future scholars as change agents. International Digital Library Perspectives, 30(3), 144-157.

Clark, J. M., Rollins, A. W., \& Smith, P. (2014). New methods for an undergraduate journal club. Bioscene, 40(1), 16-20.

Cohen, L., Manion, L., \& Morrison, K. (2017). Research methods in education. London, UK and New York, NY: Routledge.

Cowell-Meyers, K., Mainwaring, B., Dugdale, S., Kinney, C., \& Hanson, B. (2015). So you want to create a student research journal? How to craft a journal based on peer learning. The Teacher, 492-496.

Creswell, J. W., \& Plano Clark, V. L. (2007). Designing and conducting mixed methods research. Thousand Oaks, CA: Sage.

Emig, J. (1977). Writing as a mode of learning. College Composition and Communication, 28(2), 122128.

Graves, R. (2011). Representing writing: A rhetoric for change. In D. Starke-Meyerring, A. Paré, N. Artemeva, M/ Horne, \& L. Yousoubova (Eds.), Writing in knowledge societies (pp. 373-387). Fort Collins, CO: WAC Clearinghouse and Parlor Press.

Ho, A. K. (2011). Creating and hosting student-run research journals: A case study. Partnership: The Canadian Journal of Library and Information Practice and Research, 6(2), 1-10.

Marken, L. (2015). The Writing Centre as Home for an Undergraduate Journal. PowerPoint Slides. Presentation to CWCA Conference. 
Volume 28, 2018

http://journals.sfu.ca/cjsdw

Mariani, M., Buckley, F., Reidy, T., \& Witmer, R. (2013). Promoting student learning and scholarship through undergraduate research journals. Political Science and Politics, 46(4), 830-835.

Neville, P., Power, M. J., Barnes, C., \& Haynes, A. (2012). Exploring the "learning careers" of Irish undergraduate sociology students through the establishment of an undergraduate sociology student journal. Teaching Sociology, 40(2), 107-122.

Ozay, S. B. (2012). The dimensions of research in undergraduate learning. Teaching in Higher Education, 17(4), 453-464.

Provalis Research. (2017). QDA Miner: Qualitative text analysis software. Available at https://provalisresearch.com/products/qualitative-data-analysis-software/freeware/

Roberts, J. (2009). An undergraduate journal club experience: A lesson in critical thinking. Journal of College Science Teaching, 38(3), 28-31.

Sandefur, C. I. \& Gordy, C. (2016). Undergraduate journal club as an intervention to improve student development in applying the scientific process. Journal of College Science Teaching, 45(4), 52-58.

Stone, G., Jensen, K., \& Beech, M. (2016). Publishing undergraduate research: Linking teaching and research through a dedicated peer-reviewed Open Access journal. Journal of Scholarly Publishing, 47(2), 147-170. 